\title{
Weather Proverbs and Speech Acts
}

By: Abbas Lutfi, Ph.D.

University of Baghdad

Instructor, College of Education

\section{Introduction:}

Proverbs are utterances that reflect morals, life experiences and practical skills of everyday living of ordinary people. They reveal the way people look at the world and thus have a great influence on people's lives. They are sometimes employed to express strong emotions of likes, dislikes and censure, and sometimes serve to impart wisdom. They are actualized in the context of everyday communication performing the same functions, in principle, as other utterances, i.e., they serve various social functions in a linguistic community.

A proverb is not only a mere sequence of words that exhibit a certain literal meaning but it serves to offer conduct, express doubt, instruct, advise, and exhort people to either do or refrain from doing something. If so, these functions represent the so-called speech acts. The crucial question is it possible to consider weather proverbs - as part of the whole stock of proverbial utterances - speech acts? since they appear to be deeds or actions directed to a hearer rather than a string of successive words that predicts a specific linguistic meaning. The uttered of a weather proverb is actually not only speaking out words, but he is committing someone else to an action proposed by the linguistic signs a proverb is made up of For example, when someone says:

1. Red sky in the morning, sailors take warning.

2. Red sky at night, sailor's delight.

It is true that he is prophesying the future state of the weather ( a statement about weather) but he is indirectly warning his listener of heavy rain in (1) and advising him in (2) to make use of the coming fine climate( of dry nice weather).

In this respect,Yanga(1977:130 cited in Yusuf 1997) explains that :

the reason behind treating proverbs in terms of speech acts is the belief that the user of proverbs is not only uttering words but performing linguistic acts for a social purpose in a particular speech community . Proverbs ... are statements that function as deeds.

The belief that proverbs, including those pertinent to weather forecasting, perform social pragmatic functions is also emphasized by Krikmann (1999) who writes:

Proverbs do not function as mere poetic adornments of a statement of speech . They are not only used to meet man's needs for philosophical phrase mongering. As a rule, they are used for some practical, pragmatically purposes in various circumstances of everyday communication.

Thus, this paper tends to discuss the question whether weather proverbs can 
be practically deemed as speech acts in virtue of the most salient speechact theories present in the literature of pragmatics, as such utterances are usually meant to accomplish different social linguistic functions in any human society.

\section{1-Weather Proverbs:}

Long before the invention of meteorological instruments, people relied on "natural" principles to approaching weather. Weather matters and concerns have preoccupied them since the beginning of knowledge and experience. For centuries they have created proverbs ( rhymed utterances ) associated with atmospheric conditions to help explain or foretell the future state of weather. Such utterances are often based upon people's ( particularly farmers, sailors, travelers, merchants and fishermen) keen observations of climatic conditions rather than on scientific principles and evidence.

The importance of these utterances lies in the fact that they give possible and interesting information on what is likely to occur in the next few hours. As these formulaic utterances yield general advice and conduct concerning climatic aspect of life,i.e, having culture's values and beliefs )a considerable number of weather proverbs have been originated and gained currency in individual ethnic or in national languages. Moreover, weather proverbs teach us that every available opportunity must be used to advantage. That is, " one must refrain from what one cannot do ,lest one wastes energy [and] becomes a failure" (Green and Pepicello, 2000). This idea is clearly expounded in the New Testament. In Matthew 16.23, while talking to a group of fishermen, Jesus ( PEACE BE UPON HIM ) says: "When it is evening, you say, It will be fair weather, for the sky is red. ' and in the morning 'It will be stormy today, for the sky is red and threatening.' "He is not telling them about a statement of weather, rather he is encouraging them to make benefit of the fine weather in the first part of his saying ( ... fair weather ), and warning them in the second part (... stormy today \& ... red and threatening ). In accordance with what has been mentioned, the main concern of this paper is to demonstrate that weather proverbs are often intended to be speech acts rather than statements about atmospheric settings.

\section{2-Weather Proverbs and Speech Acts:}

As a well-known fact, pragmatics focuses on the investigation of the type of meaning that goes beyond what is said literally. That is, the type of meaning intended by the speaker of a weather proverb and inferred by the hearer by virtue of the context in which this proverb is inserted. The uttering of a weather proverb may involve the performance of two interrelated acts (formal and intentional). The formal act is explicitly conveyed by the grammatical form. The latter is implicitly induced from the context. The crucial act is the intentional one because it determines how the utterance is "taken to be" as well it is the one that implies the 
type of meaning intended by the speaker. The intentional (illocutionary) act is often performed via the proper enunciation of the weather proverb (Stiles, 1980:234).

Akmajian et al.(2001:387) proceed that it is so obvious that weather proverbs are not used both literally and directly ; they are often employed both nonlinearly and indirectly because people usually avoid bluntly directing their audience and resort to proverbs to soften the effect by distancing themselves from the advice or warning, letting the common truth or general wisdom implied in the proverb do the talking .Consider:

\section{Chimney smoke descends, our nice weather ends.}

This proverb indirectly offers its hearer a caution that bad weather might be expected, utilizing the metaphorical picture of a chimney whose smoke gets down as a signal to the end of a fine weather.

Though the ultimate objective of citing a weather proverb is to direct people towards something good or prevent them from doing something bad, a given proverb may be open to more than one interpretation, and this depends mainly on how the speaker intends his utterance to be taken, and how the hearer interprets and reasons the propositional content of the proverbial wording, and how these words fit the situation to which they are applied. One main interpretation is associated with the analogical relationship between the proverb image and the real- world situation . Consider the following weather proverb:

\section{The higher the clouds the better the weather.}

The semantic meaning of this proverb is derived from the connection of the proverb image ( the high clouds cause fine weather ) to the real world in which these clouds generally indicate dry air and high atmospheric pressure, associated with fair weather. Then, the pragmatic, intended meaning that the speaker aims at, is effectively determined by this semantic meaning, being based on the conventional devices a proverb exhibits (Verschueren,1997: 30).

In line with Austin (1962), the speaker of a weather proverb not only says something to make a statement about the world, but he also performs an action which affects or produces a change in the epistemic system of the hearer's mind. For example, by uttering :

\section{Rainbow in the morning gives you fair warning.}

under certain appropriate conditions, the speaker does not describe the weather state but he actually offers his interlocutor a gentle warning (i.e., fair rain will be approaching)

While enunciating this proverb, three interrelated acts are simultaneously involved: the lectionary, illocutionary and elocutionary acts.The act of uttering 
the proverb "Rainbow in the morning gives you fair warning" is referred to as the locution. This act involves the issuing of a well-formed grammatical and meaningful sentence pronounced properly (ie, the words artificially divorced om the context of utterance). The illocution refers to what is intended in saying this proverb, or what type of speech acts is meant by this proverb. In fact, this proverb is taken to be a fair warning. This is also clearly ascertained by the use of the expression " fair warning ". The per locution implies the effect that this proverb leaves on the hearer by saying it. After being alerted, the hearer might feel good ,satisfied or indifferent by this caution.

In his " Logic and Conversation ", Grice ( 1975:45f) maintains that for a conversation to be successful, the speaker of a weather proverb, being based on the cooperative principle and rationality, is supposed to provide all sufficient but no excess information and to be truthful, relevant and perspicuous. And in order to arrive at the intended meaning of the weather proverb, Grice (ibid.) adds that when we hear the proverb( expressed as a statement of weather forecasting),we first figure out its literal meaning and examine the context to which this proverb fits. Then, we reason what additional implications the speaker might have meant by uttering such a proverb. (of course, a speaker often intends to be understood. One has to bear in mind that language is not an abstract object, rather it is an instrument of social interaction. Both the speaker and hearer must restrict themselves to the 'pragmatic' rules of communication which are often realized in terms of syntactic and semantic means.) By this, we can recognize the implied intention beyond the literal meaning. We can reasonably draw out the pragmatic meaning as the speaker intends his proverb to produce some effect in an audience by means of the recognition of this intention. Furthermore, utterances, weather proverbs among them, can have more than one function .For example:

\section{Evening red and morning gray, help the travelers on his way.}

is apparently seen as a statement of weather prophecy, but implicitly, it expresses the illocutionary act of exhorting someone to travel in such a fair weather ( a red sky in the evening and gray sky in the morning both indicate dry weather approaching ). According to Sbisa and Fabbri (1980:304), the hearer can pick up the speaker's communicative intention only through conventional (linguistic) devices, and a strict relation between the syntactic and semantic properties of the uttered proverb, and the expressed intention must be postulated in terms of the "per formative hypothesis"( Sadock,1974:19).This hypothesis states that the illocutionary force of a proverbial utterance is that part of the meaning of a sentence which corresponds to the highest clause in its underlying semantic representation. That is, the illocutionary force of the proverbial utterance and the relationship this utterance mediates between the speaker and person spoken to can be specified through the utilization of the relevant per formative clause, (containing the relevant per formative verb).Thus the following weather proverb: 


\section{A wind from the south has rain in its mouth.}

can be per formatively construed as I warn you of a wind from the south because it has rain in its mouth. Despite the surface form of this proverbial utterance, it is plausible to consider the clause whose main verb is warn to be the highest agentive clause in deep syntactic-semantic structure. In this connection, Gordon and Lack off (1971:73) assume that " it is the grossest aspects of surface form that give an indication of the illocutionary force of an utterance." Further, they suggest that a sentence with a highest non-per formative clause of normal word order should be treated, in the underlying structure, as a structure containing a per formative clause of the relevant speech act. Also, in issuing this proverb, the speaker exhorts his hearer to avoid or beware such sort of weather which causes bitter cold and low pressure cell .This proverb thus can be taken to predict the speech act of warning since the result of " a wind from the south " might be not beneficial to the hearer(bringing rain).

In this respect, Yule (1996:49) contends that the speaker of the above weather proverb might assume that the intended illocutionary force will be propositionally recognized by the hearer; depending on IFID (illocutionary force indicating devices) existed in the proverb.

Likewise, to determine the illocutionary point (as indicating what a speaker aims to attain by making the particular utterance in the particular context ) from the primary locution, Allan ( 1998 ) in his "Meaning and Speech Acts" affirms that:

hearer invokes the reasonableness condition and seeks some reason for speaker's primary illocution in the context of utterance and its constituents in relation to their textual environment, the conversational maxims, and encyclopedic knowledge of many kinds... He uses his knowledge of the language and the use of language to infer from the primary locution and the circumstances of utterance what the point might be.

In the following weather proverb:

\section{Beware the bolts from the north or west;} in south or east the bolts be best.

an imperative tells hearer to beware the bolts from the north or west conjoining with a statement of a better atmospheric condition ( In south or east the bolts be best) functions as a warning. The hearer has construed this utterance as warning on the basis of his knowledge of the grammar, lexicon, semantics and phonology of the language in question.

Most weather proverbs may be seen as expressing the directive type of speech acts as a speaker, by issuing a weather proverb, might wish to do things; persuading a hearer to an opinion, alerting him of danger or getting him to do something by means of suggestion or a hint...etc. In fact, when we utter a weather proverb, we want people to do things for us or for them that are necessary and beneficial to them. We cannot ask for things that are bluntly unreasonable. The mutterer of the proverb:

\section{If bees stay at home, rain will soon come.}


If bees fly away, fine will be the day.

actually wants his hearer to do things that are necessary and beneficial to him in respect to the good weather implied in (rain and fine day).

(For the directives ,see Searle, 1976:23 \& Bach and Harnish , 1979:47-9)

\section{Weather Proverbs as Indirect Speech Acts}

In accordance with the aforementioned section, certain pragmatic points have been adopted to account for the fact that weather proverbs can be viewed as speech acts.Being proved so, are they direct or indirect speech acts ? Putting this another way, are there certain weather proverbs whose forms predict their functions? Thus, this section is devoted to the presentation of the pragmatic means that would be exploited to determine that weather proverbs are indeed indirect speech acts.

In issuing a weather proverb, the speaker intends to mean more than what he normally means on the literal level. Speakers often expect hearers to infer the intended meaning from whatever is said " by relying on their mutually shared background information, both linguistic and non-linguistic, together with general power of rationality and inference on the part of the hearer" (Allan, 1986: 204). Then, weather proverbs must be classified as indirect speech acts in the sense of Searle(1975:59ff ). For example, a speaker may utter this weather proverb:

\section{When clouds look like black smoke}

a wise man will put on his cloak.

by way of telling the hearer to do something, i.e., advising him to get rid of the cold weather( by putting on his cloak ). This proverb is incidentally intended as a statement of weather, but it is also meant primarily as a general advice postulated by way of making a statement. Searle (ibid.) expounds that, in such cases, a weather proverb that "contains the ill cautionary force indicators for one kind of illocutionary act [ statement ] can be uttered to perform, in addition, another type of ill cautionary act [advice].

Being often used as strategies dealing with our daily situations, weather proverbs can be attached to various social situations with different meanings. The multiplicity and ambiguity status of proverbial meaning may lead them to be subject to multiple interpretations. Hence, they are employed to express more than one speech act at the same time: literal or direct and no literal or indirect. The meaning of the indirect illocutionary act is to a great extent determined by the literal meaning of the words from which the proverb is comprised.Consider:

\section{When grass is dry at morning light, look for rain before the night.}

The recognition of the speaker's intention, according to $\operatorname{Dijk}(1976: 41)$, is based 
on the "perception of the meaning of the utterance [the proverb] ... consisting of a general, conventional (lexical, grammatical) part...contextually determined, meaning being a function of this general meaning " in addition to both conventional and conversational simplicities. By virtue of the features of meaning stated, this proverb is taken to express the illocutionary act of advice (primary act) which is performed by way of a statement (secondary act). Believing in the fact that a speaker is not necessarily required to use an explicit per formative utterance to perform an action, he resorts to a weather proverb to pose the intended speech act. A speaker of a proverb does not often explicitly make a promise ,advice, warning, threat, etc. We use a weather proverb, as Akmajian et al. have elaborated above, " to soften the effect by distancing ourselves from the advice". Another justification for treating weather proverbs as indirect speech acts attributes to Norrick (1985:26-7). Norrick argues that if utterances of weather proverbs mean what they say on the literal level (semantic meaning) but go on to expand this meaning idiomatically in texts (pragmatic meaning), then these utterances should be seen as cases of indirect speech acts . A speaker can utter the weather proverb:

\section{When the forest murmurs and the mountain roars,}

Then close your windows and shut your doors.

and mean what he says about forest-murmurs and mountain-roars..., while at the same time conveying to his hearer a general warning(to avoid terrible weather). The hearer derives this meaning from the literal meaning of the utterance ; the utterance indirectly communicates this meaning effectively through the use of the imperative sentence (close your window and shut your doors when the forest...).

However, Norrick (ibid. :27) points out that the use a speaker makes of weather proverbs as indirect speech acts allows him" to disguise his true feelings, to leave himself an escape route, to offer his hearer choices and to indicate real or imagined consensus ". In some situations, a speaker utilizes a proverb to avoid evaluation or judgment that might hurt others' feelings or reveal his own private preferences.

Still, another appeal to viewing weather proverbs as indirect speech acts comes from Grice(1975). He calls what is communicated by an indirect speech act an implicative. That is, a speaker of a weather proverb often generates imprimaturs in texts, particularly when he means what he says on the literal level, but he also means something more in contexts. A speaker does so by violating (what Grice refers to) conversational maxims, namely : be brief, be accurate, be relevant and be clear and perspicuous. The validity of this view is ascertained by the belief that hearers often fail to contribute relevantly to the text-interaction depending on its literal level.

Being relied on the extension of Grice's principle of conversational maxims, a further attraction for the indirectness of weather proverbs is pertinent to the idiomatic and ambiguity of their meaning. Searle (1975:76) remarks that "in order to be a plausible candidate for an utterance as an indirect speech act, a [proverbial] sentence has to be idiomatic to start with ". As a solution to this problem of 
idiomatic, he suggests that in addition to the maxims propounded by Grice, there should be an additional maxim of conversation which postulates that "speak idiomatically unless there is some special reason not to". Needless to say, most proverbs often tend to be exploited in contexts idiomatically ; their ambiguous meanings are rarely predicted from the words they are made up of. Furthermore, it is the figurative meaning rather than the literal meaning that determines how and where to use a given proverb. ( Figurative meaning is one defining criterion of the proverb.)

In brief, one can conclude that since most weather proverbs are idiomatically and metaphorically employed, and their meanings are often denoted indirectly, not literally, then, they must be seen as instances of indirect rather than direct speech acts.

\section{Summary}

It has been noted that weather proverbs ( throughout the observation of the collected data consisting of 75 weather proverbs) are always indirectly exploited to express the directive speech acts of warning, advising, exhorting, urging, prophesying...etc, as this is often associated with the fact that in saying such proverbial utterances, the speaker expects or wants the hearer to do something in accordance with the proposition implied in the wording of the proverb in question. But, it is not always the case that there is only one illocutionary force for a single weather proverb; for there are many instances in which a single proverb can be utilized to express more than one illocutionary force,(all cases of indirect speech acts, discussed above, have shown that a weather proverb can be a combination of two illocutionary forces: direct/literal and indirect/intentional.) The problem that one encounters in the pragmatic analysis of weather proverbs is that how to account for the intentional meaning of the proverbial utterances. It is not easy to induce the pragmatic meaning of the given proverb, and this requires the hearer to exert an extra effort to infer the speaker's intended meaning. This is simply because knowing the literal and figurative meaning, and the relationship between them is not sufficient for the hearer to arrive at the speaker's intention; he is also required to investigate the meaning that is derived from the application of a given proverb to its appropriate situation in addition to other extra information, linguistic and non-linguistic.

We have concluded that weather proverbs are special cases of indirect speech acts which are associated with atmospheric conditions. These acts are uttered and performed on the condition that they are related to instances of weather broadcasting ,i.e., generally, they either exhort their hearers to make use of a fine weather or to avoid unhappy weather. 


\section{References}

- Akmajian, A.; R. Demers ; A. Farmer and R. Harnish (2001) Linguistics: An Introduction to language and Communication $5^{\text {th }}$ ed. Cambridge: The MIT Press.

- Allan, K. (1986) Linguistic meaning Vol.2. New York : Rutledge and Kegan Paul,Inc.. - (!998) Meaning and Speech Acts. Monash : Monash Univ. Press.

- Austin, J. (1962) How to Do Things with Words. Oxford : Oxford Univ. Press.

- Bach, K. (1979) Linguistic Communication and Speech Acts . Cambridge : The MIT Press.

- Dijk, J. V. van (1976) Pragmatics of Language and Literature. Amsterdam : North-Holland

Publishing Co.

- Gordon, D. and G. Lakoff (1971) "Conversational Postulates".In Papers from the Seventh

Regional Meeting of the Chicago Linguistic Society. Chicago: Chicago Linguistic Society.

- Green, Th. and W. Pepicello ( 2000 ) " The Proverb and Riddle as Folk Enthymemes". In

Deproverbio Vol.6, No.2.

- Grice, H. P. (1975) "Logic and Conversation". In P. Cole and J. L. Morgan, eds Syntax and Semantics 3: Speech Acts . New York: Academic Press, pp.38-58.

- Krikmann, A. (1999) " Some Additional Aspects of Semantic Indefiniteness of Proverbs". In Deproverbio Vol. 5., No. 2.

- Norrick, N. (!985) How Proverbs Mean : Semantic Studies in English Proverbs.Berlin : Mouton Publishers.

- Sadock, J. (1974) Toward a Linguistic Theory of Speech Acts . New York :Academic Press.

- Sbisa, M. and P. Fabbri (1981) " Models (?) for a Pragmatic Analysis ". In Journal of

Pragmatics 4 , pp.301-19.

- Searle, J. (1975) "Indirect Speech Acts". In Syntax and Semantics, pp. 59-82.

(1976) "A Taxonomy of Illocutionary Acts". In Language in Society 5, pp. 1-23.

- Stiles, W. (1981) " Classification of Intersubjective Illocutionary Acts ". In Language in Society 1, pp. 233-249.

- Vershueren, J. (1999) Understanding Pragmatics. London : Arnold.

- Yule, G. (1996) Pragmatics. Oxford : Oxford Univ. Press.

- Yusuf, Y. (1997) "A Speech Act Study of English and Yoruba Proverbs ".(Unpublished Ph.D. Thesis), University of Lagos.

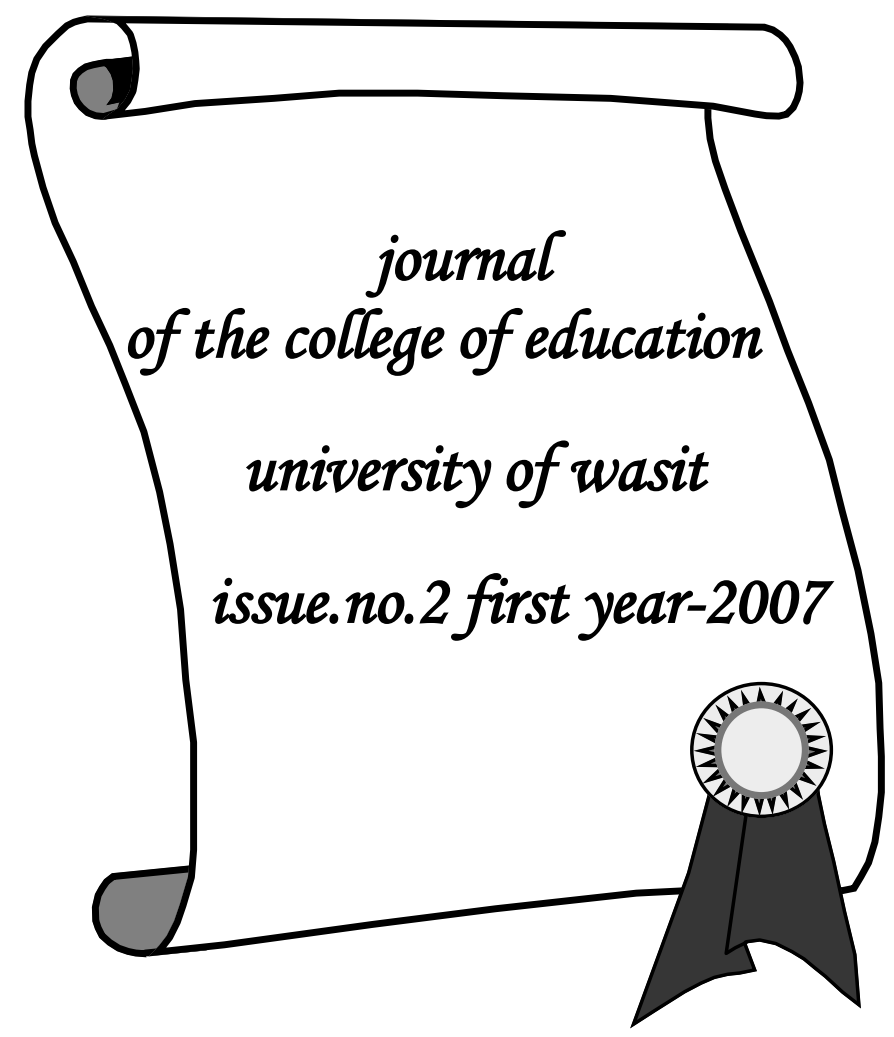

